\title{
BORGES, O ETERNO CAÇADOR DE VAGA-LUMES
}

\section{Lúcia Peixoto Cherem*}

O reflexo

Tudo no mundo está dividido em duas partes, das quais uma é visível e outra invisível. A visível nada mais é do que o reflexo da invisível.

Zohar, 1, 39. Texto compilado por Jorge Luis Borges em Livro dos Sonhos

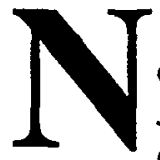

esse trabalho, procurarei focalizar a relação entre parte da obra de Jorge Luis Borges e os preceitos do budismo, tema que ocupou o escritor em vários momentos de sua vida. $O$ que me levou a investigar essa relação foi o que nos disse o cineasta Edgardo Cozarinsky a propósito de sua leitura da obra de Borges durante o curso que proferiu na Universidade de São Paulo em 1999: "Borges sempre nos escapa; por onde quer que tentemos fixá-lo, sempre estaremos desnorteados à sua procura."

Cozarinsky falou-nos também da tendência do autor argentino em apresentar ao leitor a dissolução do próprio eu e a ilusão da individualidade criadora, original, temas fundadores do budismo. Essa maneira de apresentar a obra borgiana pareceu-me justa, porque era essa a experiência de leitura que também

* Professora de Literatura e Língua Francesa da UFPR. 
CHEREM, L. P. Borges, o eterno caçador...

eu conheci ao ler Borges, mas que não sabia definir. E foram essas as perguntas que me fiz: por que Borges provoca essa sensação no leitor, como ele consegue perturbá-lo a ponto de fazê-lo sentir-se perdido e sempre em estado de busca, como um caçador de vaga-lumes, que, além de fixar o olhar na noite, deve estar atento à trajetória do inseto? Em seguida, deve esperar que a luminescência reapareça para poder seguir o vaga-lume no ar, já que durante o vôo ele se torna praticamente invisível, só ficando visível em função dessa luminescência que acende e apaga? Parece que, para Borges, ler também era como caçar vagalumes e essa busca de um inconstante e abrangente leitor talvez tenha se transferido para a sua taefa de escritor.

Nessa busca há também uma aproximação com o budismo: os monges budistas mais sábios, quando têm a seu lado os neófitos, nunca esclarecem as dúvidas desses que estão se iniciando na doutrina budista. Quando um deles faz uma pergunta a um monge experiente, este sempre lhe dará uma resposta aparentemente absurda, para que o iniciante procure a solução por si mesmo.

A dissolução do eu, o desdobramento de si mesmo, as ilusões do mundo terreno e a busca incessante por um sentido claro das coisas, ainda que construído, estão presentes no budismo e foram temas instigadores para Borges. $E$ a relação desses temas budistas com parte de sua obra que tentarei estabelecer a seguir.

\section{Borges e o Budismo}

Em Sete Noites, livro de conferências proferidas pelo autor em 1977, o quarto capítulo chama-se Budismo, em que Borges menciona apenas o essencial dessa religião. As duas características do budismo que ele mais aprecia são: a tolerância e a essencialidade. Ele nos diz que é preciso apenas sentir de corpo e alma as quatro nobres verdades presentes no primeiro sermão do Jardim das Gazelas de Benares para ser budista: trata-se da apresentação dos primeiros preceitos ditados por Buda, o Lúcido. Quais seriam as quatro nobres verdades? "A nobre verdade do sofrimento, a nobre verdade da origem do sofrimento, a nobre verdade da cessação do sofrimento, a nobre verdade do caminho da cessação do sofrimento."1

1 Paroles de Bouddha (Tirées de la tradition primitive): Textes choisis, présentés et traduits du chinois par Jean Eracle. Paris: Editions du Seuil, 1991. p. 25. 
CHEREM, L. P. Borges, o eterno caçador...

O caminho da cura levará ao Nirvana. Os preceitos aproximam-se de procedimentos medicinais e não é à toa que Borges diz, em algum de seus textos, que esse tipo de cura é o que propõe, em nosso século, a psicanálise. No seu livro Buda, Borges cita as palavras do profeta: "Assim como o oceano, que é tão vasto, tem um único sabor (o do sal), também o sabor da lei tem sempre o sabor da salvação.",2

É no respeito à doutrina budista que será encontrada a salvação. Borges nos diz ainda que as outras religiões exigem demais da nossa credulidade, ao contrário do budismo: "Podemos ser bons budistas e negar que o Buda existiu. Melhor: podemos e devemos pensar que não é importante acreditar no fator histórico. O que importa é a crença na Doutrina. Mas a lenda do Buda é tão bela que não podemos deixar de mencioná-la."3

Nessa afirmação, vemos que Borges apreciava essa característica da religião que leva o budista a concentrar-se nos preceitos sem ser obrigado a crer na existência do próprio Buda. No entanto, a história do Buda e o mito dela decorrente o fascinam e, a partir deles, Borges permite-se produzir diferentes tipos de escrita: os ensaios sobre o budismo, entre os quais o quarto capítulo de Sete noites, o livro Qué es el budismo?, traduzido para o português como Buda, obra assinada também por Alícia Jurado, e ainda o texto Formas de una leyenda em Otras inquisiciones; ao mesmo tempo, temas budistas inspirarão contos e poemas, fazendo parte integrante de sua obra literária.

\section{Formas de una leyenda - Borges entre o claro e o escuro das coisas}

Nesse pequeno ensaio, que faz parte do livro Otras inquisiciones, Borges faz uma análise do mito do Buda. Parte da declaração histórica de Siddharta, o príncipe do Nepal, que, ao ver um velho, um doente e um morto, opta pela vida de asceta. Essa declaração faz parte de um dos livros do cânone. Já em outro livro, há a parábola dos cinco mensageiros secretos, enviados pelos

2 BORGES, J. L.; JURADO, Alícia. Buda. Trad. por Claudio Fornari. 3. ed. Rio de Janeiro: Bertrand Brasil, 1987. p. 103.

3 BORGES, J. L. Sete noites. Trad. por João Silvério Trevisan. 2. ed. São Paulo: Max Limonad, 1983, p. 96.

4 BORGES, J. L. Obras completas. t. 1. Buenos Aires: Emece Editores, 1974. p. 740. 
deuses, cuja mensagem seria: "nuestro destino es nacer, caducar, enfermar, sufrir justo castigo y morir."

A partir desses dois relatos, Borges comenta que a realidade talvez seja demasiadamente complexa para a transmissão oral; por isso, a lenda teria recriado o real para poder viajar pelo mundo de boca em boca, guardando aquilo que é essencial para a divulgação da doutrina budista. Borges afirma: "En la parábola y en la declaración figuran un hombre viejo, un hombre enfermo y un hombre muerto; el tiempo hizo de los dos textos uno y forjó, confundiéndolos, otra historia."6

Em seguida temos a lenda:

Siddharta, el Bodhisattva, el pre, Buddha, es hijo de un gran rey, Suddhodana, de la estirpe del sol. La noche de su concepción, la madre sueña que en su lado derecho entra un elefante, del color de la nieve y com seis colmillos. Los adivinos interpretan que su hijo reinará sobre el mundo o hará girar la rueda de la doctrina y enseñará a los hombres cómo librarse de la vida y la muerte. El rey prefiere que Siddharta logre grandeza temporal y no eterna, y lo recluye en un palacio, del que han sido apartadas todas las cosas que pueden revelarle que es corruptible.

No entanto, os planos do pai de Siddharta caem por terra, porque ao sair quatro vezes do palácio, este encontra personagens simbólicos que lhe mostram a precariedade da existência: um velho, um doente e um morto. Por último, encontra um homem que traz a paz em seu rosto: trata-se de um monge. A partir daí, o Buda toma a decisão de abandonar sua vida para seguir seu caminho de eleito.

Borges, nesse texto, faz comentários sobre várias versões dessa lenda. $O$ mais importante deles é o que analisa a compilação em sânscrito impuro (Lalitavistara). Segundo esse texto, o Buda é que criou todas as situações, encontrando as figuras simbólicas, porque já era poderoso.

Foucher, um indólogo respeitado, acredita que essa interpretação é feita pelos autores por eles terem dificuldade em aceitar a ignorância do príncipe em relação à realidade.

5 BORGES, Obras completas..., p. 740.

6 BORGES, Fomas..., p. 740.

7 Ibid., p. 743. 
É logo em seguida que Borges faz um comentário pessoal do enigma, propondo a sua própria visão: "el enigma merece, a mi entender, otra solución. El Buddha crea las imágenes y luego inquiere de un tercero el sentido que encierran. Teológicamente cabria talvez contestar: el libro de la escuela del Mahayana, que enseña que el Buddha temporal es emanación o reflejo de un Buddha eterno: el del cielo ordena las cosas, el de la tierra las padece o las ejecuta."8

Borges comenta que essa divisão do eu, em nosso século, com outra metodologia ou vocabulário, é representada pelo inconsciente. A psicanálise seria uma outra forma de explicar essa duplicidade do ser. Pois bem, a posição de Borges se revela de forma clara: ele abandona as sutilezas dogmáticas e prefere lembrar que todas as religiōes do Industão e, principalmente o budismo, ensinam que o mundo é ilusório.

A vida de Buda seria um jogo ou um sonho, como o próprio universo. Segundo Borges, o próprio Siddharta teria sonhado toda a sua história, já que na base do mito há um sonho, o da mãe de Siddharta.

Para o escritor argentino, o irreal foi invadindo e substituindo a história.

Essa forma de esclarecer o enigma é sem dúvida uma opção bastante borgiana. No entanto, essa clareza dura muito pouco, porque o próprio Borges desconfia de sua explicação e é com palavras que aceitam a obscuridade que ele termina Formas de una leyenda: "La cronología del Indostán es incierta, mi enudición lo es mucho más; Koeppen y Hermann Beckh son quizá tan falibres como el compilador que arriesga esta nota; no me sorprendería que mi historia de la leyenda fuera legendaria, hecha de verdad sustancial y de errores accidentales". 9

Se no início, ele tenta se colocar, esclarecendo sua posição em relação à história e à lenda relacionadas ao Buda, aos poucos, após haver criado espaço, também ilusório, para a clareza das idéias, ele vai nos preparando outra vez para lançar-nos no espaço absurdo de incertezas, impossível de ser explicado, quer pela história, quer pelo conhecimento profundo dos textos e sua interpretação, já que, havendo textos, certamente houve recriação. E é então, segundo Borges, o conhecimento da mitologia que vai prevalecer no entendimento do universo.

Em Formas de una leyenda, fica evidente a importância que a erudição desempenha na obra de Jorge Luis Borges.

Segundo Ricardo Piglia, se por um lado podemos inserir Borges na tradição gauchesca, na grande tradição oral e épica do século XIX, por outro

8 BORGES, Formas..., p. 742.

9 Ibid., p. 743. 
CHEREM, L. P. Borges, o eterno caçador...

lado, encontramos "el manejo de la cultura, el cosmopolitismo, la circulación de citas, referencias, traducciones, alusiones."10

A utilização de todo esse material cultural, segundo Piglia, é levada ao extremo na obra de Borges: "En Borges la eqrudición funciona como sintaxis, es un modo de darle forma a los textos." 11

A utilização da erudição é resultado das leituras que faz: seu gosto pela enciclopédia, pelos manuais de divulgação levam-no também a se interessar e a fazer compilações de vários assuntos, como é o caso do budismo. O livro Que és el budismo? é um dos exemplos de texto difusor da cultura que, para Borges, não apresentava fronteiras, pois sendo argentino sentia-se livre para receber qualquer tipo de influência e interessar-se por qualquer texto. Via a cultura de seu país como herdeira de toda a cultura ocidental. Ora, refletir também sobre a cultura do Oriente era para ele um prazer e uma busca incessantes.

No livro Que és el budismo? Borges nos apresenta o Buda legendário logo no primeiro capítulo e o Buda histórico vem em seguida. $O$ autor tem sempre a preocupação em fornecer dados históricos, mas faz questão de assinalar que a lenda, o mito se sobrepõem ao homem real. Para ser budista, não é necessário acreditar que o Buda existiu de fato. $O$ fundamental é respeitar a lei do budismo, ou seja, o texto escrito onde figuram as quatro nobres verdades $e$ a senda óctupla (hábito hindu de dividir e subdividir) que devem ser sentidas e não somente lidas.

Acreditar na existência de um príncipe do Nepal que chegou a ser o Buda há dois mil e quinhentos anos não tem grande importância. Ao contrário, o que é fundamental é acreditar na Doutrina. E um dos temas de meditação nos mosteiros da China e do Japão é justamente a dúvida em relação à existência de Buda, uma das dúvidas necessárias para se alcançar a verdade.

Para seguir a Doutrina, faz-se necessário o conhecimento das leis. Passa-se obrigatoriamente pela escrita. Quem pode garantir que os textos não foram reinterpretados e reescritos ao longo do tempo? Para Borges, história e lenda não se dissociam mais no mundo da escrita.

$\mathrm{Na}$ base da religião budista está o mito, a lenda cuja beleza não pode deixar de ser mencionada. Para Borges, esse é um dos aspectos atraentes dessa religião: ele apreciava o lado estético do budismo. Pouco importa se a lenda fala de um elefante que entra no flanco da rainha. Não há preocupação com o real, pois trata-se de um sonho contado com beleza. $\mathrm{O}$ elefante branco representa $O$

10 PIGLIA, Ricardo. Sobre Borges. Cuadernos de Recienvenido - Borges 100. São Paulo: Humanitas, 1999. p. 12.

11 PIGLiA, p. 12. 
que há de mais pacífico e doce na Índia. E Borges nos diz: “Além de ser uma religião, o budismo é uma mitologia, uma cosmologia, um sistema metafísico, ou melhor, uma série de sistemas metafísicos que não se entendem e discutem entre si." 12

Mesmo a parte terrena do mito, como já foi assinalado, é explicada através do sonho da rainha Maya, mulher do rei Suddhodana.

Essa relação do sonho com a base das religiões está no prólogo do Livro dos sonhos em que Borges diz não ser impossível que as mitologias e as religiões tenham origem em sonhos e pesadelos.

\section{Alguns dos sonhos de Borges e um sonho por ele compilado}

Outra característica importante do budismo e que está em Borges é a crença de que somos espectadores, testemunhas e não atores das coisas: "Quando o corpo sutil ou a alma psíquica intui esta verdade, cessa a união da alma com a matéria. A alma e os dois corpos, o material e o sutil, se desintegram. A alma libertada de seus corpos não se reintegra a uma alma total, mas atinge a inconsciência absoluta. Os textos comparam-na a um espelho que nada reflete, um espelho vazio." 13

Outra forma de entender essa postura de espectador diante da vida é a leitura dos textos do Livro dos Sonhos. Já no prólogo, ele nos fala justamente disso: "Em um ensaio do The Spectator (1712), compilado neste volume, Joseph Addison observou que, quando sonha, a alma humana, desligada do corpo, é, a um tempo, o teatro, os atores e a platéia. Podemos acreditar que é também a autora da fábula que está vendo."14

\section{Sonho infinito de Pao $\mathrm{Yu}^{15}$}

Segue a transcrição integral de um dos sonhos compilados por Borges:

12 BORGES, Sete noites..., p. 96.

13 BORGES; JURADO, Buda..., p. 29.

14 BORGES, Jorge Luis. Livro dos sonhos. São Paulo: Círculo do Livro, 1984. p. 5.

15 lbid., p. 13. 
CHEREM, L. P. Borges, o eterno caçador...

Pao Yu sonhou que estava em um jardim idêntico ao de sua casa. Será possível, pensou, que haja um jardim idêntico ao meu? Acercaram-se dele algumas donzelas. Pao Yu, atônito, disse a si mesmo: Alguém terá donzelas iguais a Hsi-Yen, a Pin-Erh e a todas as de minha casa? Uma das donzelas exclamou: "Aí está Pao Yu. Como terá chegado até aqui?" Pao Yu pensou que o haviam reconhecido. Adiantou-se e disse-lhes: "Estava caminhando; por casualidade cheguei até aqui. Caminhemos um pouco". As donzelas riram. "Que desatino ! Confundimos-te com Pao Yu, nosso amo, porém não és tão garboso como ele". Eram donzelas de outro Pao Yu. "Queridas irmãs", disse a elas, "eu sou Pao Yu. Quem é vosso amo?" "É Pao Yu”, responderam. "Seus pais lhe deram esse nome, composto dos caracteres Pao (precioso) e Yu (jade), para que sua vida fosse longa e feliz. Quem és tu para usurpar seu nome?" E se foram, rindo.

Pao Yu ficou abatido. "Nunca me trataram tão mal. Por que me detestaram essas donzelas? Existirá, de fato, um outro Pao Yu? Tenho que averiguar." Movido por esses pensamentos, chegou até um pátio que the era familiar. Subiu a escada e entrou em seu quarto. Viu um jovem deitado; ao lado da cama, rindo, umas mocinhas faziam trabalhos domésticos. O jovem suspirava. Uma donzela lhe disse: "Que sonhas, Pao Yu? Estás aflito?" "Tive um sonho muito esquisito. Sonhei que estava em um jardim e que não me reconhecíeis e me deixáveis só. Eu vos segui até a casa e me encontrei com outro Pao Yu dormindo em minha cama." Ao ouvir o diálogo, Pao Yu não se conteve e exclamou: "Vim em busca de um Pao Yu; és tu". O jovem levantou-se e o abraçou, gritando: "Não era um sonho; tu és Pao Yu". Do jardim uma voz chamou: "Pao Yu!" Os dois Pao Yu estremeceram. O sonhado se foi; o outro dizia: "Volta logo, Pao Yu". Pao Yu despertou. Sua donzela Hsi-Yen the perguntou: "Que sonhavas, Pao Yu? Estás aflito?" "Tive um sonho muito esquisito. Sonhei que estava em um jardim e que não me reconhecíeis..."

Tsao Hsue-king, Sonho do aposento vermelho (c. 1754).

Pao Yu sonha consigo mesmo em seu próprio jardim. O ser sonhado e o homem que sonha tentam se encontrar. Há muita alegria na ilusão desse encontro. Mas o sonhado se vai e a história relatada às donzelas que cercam Pao Yu é sempre a mesma.

Esse sonho seria uma metáfora da própria obra de Jorge Luis Borges, por possuir duas características: a primeira delas estaria ligada à sensação de história infinita que sua obra nos deixa. A segunda está relacionada à busca de si mesmo; 
o tema do desdobramento do próprio eu foi trabalhado por Borges mais de uma vez, como se pode ver no texto Borges y yo. Não se trata aí de um sonho. É o próprio Borges consciente da existência de dois eus: o Borges de carne e osso, que vive simplesmente, que come batatas cozidas em restaurantes modestos de Buenos Aires, que caminha e se demora mecanicamente para olhar el arco de un zaguán y la puerta cancel. ${ }^{16}$ Esse Borges consciente de seu corpo, que sente o sabor do café e que admira a prosa de Stevenson. O outro Borges compartilha com ele esses prazeres, mas os converte em atributos de un actor. ${ }^{17}$ Trata-se do Borges sonhado, o Borges que todos admiram, que viaja para proferir conferências. Esse Borges vai se distanciando do Borges matéria porque já é o Borges erudito, lido, o Borges construído, que exige sempre mais da imaginação do Borges criador, mais modesto e mais consciente das suas limitações. No entanto, este consente a existência do Borges célebre: "Yo vivo, yo me dejo vivir, para que Borges pueda tramar su literatura y esa literatura me justifica." 18

Logo em seguida, vem à consciência o fato de a escritura não poder justificar completamente sua vida, já que tudo que se produz de bom faz parte da linguagem ou da tradição. Encerra suas palavras, dizendo que vai cedendo tudo ao outro Borges e que não adianta parar de fugir dele: "Yo he de quedar en Borges, no en mi (si es que alguien soy)."

Sua vida é uma fuga e já não se sabe qual dos dois Borges está escrevendo o texto. Mais uma vez percebemos que depois de, engenhosamente, encontrar uma explicação para o desdobramento do eu - apresentando ao leitor essa divisão com uma clareza assustadora, ele nos lança novamente na confusão, tornando-se obscuro, complexo, principalmente, quando diz: "Mi vida es una fuga y todo pierdo y todo es del olvido, o del otro". 20

Por isso, como caçadores de vaga-lumes, nós, leitores, tateamos no escuro à procura desse escritor que quanto mais se explicita, mais se turva diante dos nossos olhos.

Voltando aos relatos de sonhos, Borges acha perigosa, mas atraente, a idéia de que os sonhos constituiriam "o mais antigo e não menos complexo dos gêneros literários". 21

16 BORGES, J. L. Borges y yo. In: Obras completas. t. 1. Buenos Aires: Emece Editores, 1974. p. 808.

17 Ibid.

18 lbid.

19 lbid.

20 Ibid.

21 BORGES, Livros dos sonhos..., p. 5. 
CHEREM, L. P. Borges, o eterno caçador...

O sonho da corça branca

As imagens de alguns sonhos por si só teriam uma ordem estética, despertariam a vontade do poeta Borges em trabalhar seu sonho, transformandoo num poema de grande beleza como "A corça branca":

De que agreste balada da verde Inglaterra,

De que lâmina persa, que região arcana

Das noites e dias que o nosso ontem encerra

Veio a corça branca com que sonhei esta manhã $?^{22}$

O instante captado é narrado com muito cuidado e a cena é revelada ao leitor, guardando a leveza do sonho.

Duraria um segundo. Via-a cruzar o prado

E perder-se no ouro de uma

Tarde ilusória,

Leve criatura feita de um pouco de memória ${ }^{23}$

No entanto, a corça, por mais preciosa e bela que lhe pareça, não lhe pertence, porque o poeta não se considera agente de nada; os sonhos lhe ocorrem, como os fatos da vida.

As deidades que regem este curioso mundo

Deixaram-me sonhar-te, porém não ser teu dono;

Talvez numa esquina do porvir profundo

Volte a encontrar-te, corça branca de um sonho. ${ }^{24}$

Sc ele tivesse o poder de forjar os sonhos, tentaria reencontrar a corça branca porque sente-se como ela, irmanado a ela, compartilhando a mesma fragilidade. E conclui seu poema assim:"Também eu sou um sonho lúcido que perdura um pouco mais que o sonho do prado e da loucura." 25

BORGES, Livro dos sonhos..., p. 5.

lbid.

Ibid.

25 Ibid., p. 66. 
Ser um sonho lúcido parece ser o destino de Borges. Ter consciência da ilusória existência física, ter consciência de ser parte ínfima da grande natureza aproximam-no dos preceitos budistas.

Borges descreve com tal humanidade certos animais em seus textos que se transforma um pouco neles quando os descreve. E aqui não poderíamos deixar de pensar no tigre, talvez o animal que mais o fascine.

\section{Dreamtigers}

O relato da experiência de sonhar tigres inicia-se pela revelação de uma adoração: "Durante a infância exerci com fervor a adoração do tigre: não o tigre esbranquiçado dos camalotes do rio Paraná e da confusão amazônica, mas sim o tigre raiado asiático, real, a quem somente podem enfrentar os guerreiros, encastelados no dorso de um elefante." 26

O tigre que o fascina aqui é o tigre distante, observado nas enciclopédias ou no zoológico, embora no fim de sua vida tenha escrito o texto Meu último tigre em que descreve seu encontro físico com um deles, chegando a tocá-lo.

No sonho descrito anteriormente, Borges nos fala da lucidez durante $o$ sono. Quando está sonhando, percebe que se trata realmente de um sonho e nesse momento, iludido pelo poder de sua individualidade, decide produzir um tigre, seu animal predileto. Mas é incapaz de fazê-lo: "Oh! Incompetência! Meus sonhos não sabem nunca engendrar a fera desejada. O tigre aparece, sim, porém dissecado e débil, com impuras variações de forma, ou de um tamanho inadmissível, ou muito fugaz, ou parecendo-se mais com um cachorro ou com um pássaro."27

Como não pensar, ao ler esse relato, no conto La escritura del Dios? O tigre mora ao lado de Tzinacán e no pêlo do animal encontra-se o enigma, a inscrição divina que o homem encarcerado persegue. Porém, antes da revelação, Tzinacán tem um sonho que o ajuda a encontrar seu Deus. Sonha com grãos de areia que proliferam e acabam quase o sufocando. Tzinacán é salvo pela consciência de estar sonhando:"Compreendí que estaba soñando; con un vasto esfuerzo me desperté. El despertar fue inútil; la innumerable arena me sofocaba."28

26 BORGES, Livro dos sonhos..., p. 66.

27 Ibid., p. 132.

28 BORGES, Jorge Luis. La escritura del Dios. In: Obras completas. Buenos Aires: Emece Editores, 1974. p. 598. 
Então alguém lhe fala: "No has despertado a la vigilia, sino a um sueño anterior. Ese sueño está dentro de otro, $y$ así hasta lo infinito, que es el número de los granos de arena. El camino que habrás de desandar es interminable y morirás antes de haber despertado realmente."29

Mas Tzinacán não se rende e consegue gritar: "Ni una arena soñada puede matarme ni hay sueños que estén dentro de sueños." 30

Despertado, sente-se feliz em estar novamente no cárcere: há os prazeres terrenos, ainda que míseros, que é capaz de sentir: a presença do tigre, a obscuridade, a luz. Só então ocorre o encontro com a divindade e Tzinacán conhece o êxtase: é capaz de compreender a trama total do universo e que ele, Tzinacán, é apenas um fio dessa trama, nada mais. Além desse entendimento, decifra a escritura do pêlo do tigre. Escritura que ele havia estudado tantos anos e que agora se revelava.

Mas, antes da revelação, o fascínio que a escritura no pêlo do tigre exercia sobre o narrador foi fundamental para a construção do texto. É na descrição do tigre, em suas manchas, que reside o valor estético do texto: é o mesmo fervor estético do menino Borges diante do tigre no zoológico. Revelação, tentativa de compreensão do mundo, para Borges, estão intimamente ligadas à experiência estética. Por isso, sua admiração pelo budismo, já que também essa religião não separa estética e veracidade dos fatos, não privilegia a história em detrimento da beleza do mito.

Tzinacán não é budista, é claro, está ligado às tradições de deuses mexicanos, mas não se pode negar certas aproximações: ele percebe que é somente um fio de toda a trama da vida, que só existe em função dos outros e vice-versa (seu inimigo é um outro fio). Então, de que lhe adiantaria revelar a escritura, se ele já se transformou no nada que realmente é? "Ya no me acuerdo de Tzinacán."

Quem conheceu os mistérios do universo não pode mais se ocupar da trivialidade da vida humana. E Tzinacán fazia parte do mundo ilusório. Agora, esse novo eu tem consciência da inutilidade das lutas humanas e compreende que o universo não passa de um sonho: "Por eso no pronuncio la fórmula, por eso dejo que me olviden los días en la oscuridad."

É mais ou menos o que nos disse o próprio Borges no texto de Sete noites sobre o budismo:

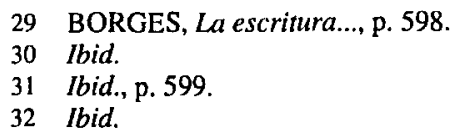


CHEREM, L. P. Borges, o eterno caçador...

É preciso chegar à compreensão de que o mundo é uma aparição e um sonho, que a vida é sonho [...] Nos mosteiros budistas, um dos exercícios é assim: o neófito precisa viver cada minuto de sua vida e vivê-lo plenamente. Deve pensar: "Agora é meio-dia. Agora estou atravessando o pátio". Mas ao mesmo tempo, deve pensar que o meio-dia, o pátio e o superior são irreais - tão irreais quanto ele e seus pensamentos. Na verdade, o budismo nega o eu. ${ }^{33}$

A desilusão e a negação do eu são fundamentais para o budismo. Não existe o sujeito, o que existe é uma série de estados mentais. Também compartilhava dessa idéia Macedonio Fernández, escritor admirado por Borges.

\section{Macedonio Fernández: um budista fora da lei}

No prólogo de uma seleção de textos de Macedonio Fernández, ${ }^{34}$ Borges relaciona a personalidade do escritor a alguns preceitos budistas.

Ao revelar-nos sua visão da vida intelectual de Macedonio, Borges acaba revelando a si mesmo as diferenças fundamentais entre os dois: a Macedonio a suma do tempo não preocupava, pois a erudição para ele era mais exibicionismo do que um meio para refletir. Por isso, Borges lembrou-se de Macedonio ao ler sobre a existência de mosteiros budistas nos quais o mestre costuma queimar livros canônicos, com a intenção de mostrar aos neófitos que não é na letra que reside a vida, mas no espírito.

Macedonio tinha como tema preferido a essência onírica do Ser, por isso Borges fez referência, em uma de suas conversas com ele, à história, do século $\mathrm{V}$ a.C., de um chinês que havia sonhado que era uma mariposa. Ao despertar, já não era capaz de saber se era um homem que havia sonhado ser uma mariposa ou uma mariposa que sonhava ser um homem. Borges toca aí numa questão interessante do budismo: a da transmigração, a reencarnação em outros corpos humanos ou em animais.

No entanto, Macedonio não dava muita importância a essas histórias contadas a ele por Borges, que pretendia mostrar a seu contemporâneo que o

33 BORGES, Sete noites..., p. 96.

34 BORGES, J. L. Prólogos com um prólogo dos prólogos. Rio de Janeiro: Rocco, 1985. p. 69. 
CHEREM, L. P. Borges, o eterno caçador...

budismo poderia ser útil às reflexões do amigo. Porém Macedonio preferia continuar a pensar sozinho, apesar de ter consciência da ilusão do sujeito. Negava-se a refugiar-se nos livros, preferia enfrẹntar o vazio de que somos feitos de frente.

Borges nos diz ainda que "Macedonio era um contemplativo puro que às vezes condescendia em escrever e muito raramente em publicar." ${ }^{35}$ Precisava estar sempre pensando, mas não estava preocupado com os registros de seus pensamentos: quando mudava de endereço, não levava seus manuscritos sobre metafísica. Deixava-os nas gavetas porque "supor qựe se possa perder algo era uma pretensão, já que a mente humana é tão pobre que está condenada a encontrar, perder ou redescobrir sempre as mesmas coisas". ${ }^{36}$

Em um texto de Macedonio Fernández sobre o escritor argentino Evar Mendez, podemos ver o que ele pensava do prosador Jorge Luis Borges. Em Mendez, Macedonio enxerga o indivíduo, vê uma vida confessada. E em seguida, refere-se a Borges: "Tenemos artistas de dramática riquísima como Banchs y, en otra vocación que la de Banchs, a Jorge Luis Borges, el mejor dotado prosista de habla española hasta hoy a juicio de mi incompetencia. Pero tanto Banchs, y más aún a Borges, sólo se les conoce la inteligencia."37

Em Borges, haveria um afã de ocultar-se que Macedonio não aprovava. Borges tinha consciência dessas diferenças e sabia que Macedonio vivera na paixão e na meditação, sem ter os livros como escudo para enfrentar as vicissitudes da vida.
A humildade de Borges.
Quando o vi
pela primeira vez e lhe mostrei
o coração repleto de admiração,
me respondeu: : "Se algun día te dás cuenta
de que no soy lo que tú te imaginas,
no digas que no te avisé."
Essa frase continua
impregnando a minha vida.

Marli de Oliveira

A força de uma paixão (82-84)

35 BORGES, Prólogos..., p. 66.

36 Ibid., p. 70.

37 FERNÁNDEZ, Macedonio. Obras completas: relatos, cuentos, poemas y misceláneas. t. 7. Buenos Aires: Ediciones Corregidor, 1987. p. 152. 
CHEREM, L. P. Borges, o eterno caçador...

\section{Conclusão}

Gostaria rapidamente, para concluir, de relacionar um quadro da pintura chinesa do século XVI com alguns aspectos encontrados na literatura de Borges. Para o taoísmo, a natureza se impõe ao homem. É o que fica evidente na reprodução da obra de Chou Ch'en, intitulada Dreaming of immortality in a thatched cottage, que encerra esse trabalho.

A figura humana, quase sempre em estado de contemplação, perde-se na natureza. Nem sempre a perspectiva e as proporções são respeitadas, justamente para que a supremacia da natureza se evidencie aos olhos do observador. Dessa forma, aquele que observa o trabalho pode ter noção do estado de contemplação vivido diante da natureza grandiosa pelo personagem.

Esse quadro, que não se sabe ao certo se é de autoria de Chou Ch'en, fez-me pensar particularmente em alguns textos de Borges, porque se trata da reprodução de um sonho. O homem sonha que atingiu a imortalidade através de práticas taoístas. O corpo do personagem tornou-se mais leve que o corpo real, reproduzido também em sua casa à direita. A obra divide-se em duas: do lado esquerdo, temos a flutuação do homem e poucos detalhes do mundo real, pois o personagem sonhado encontra-se em um mundo essencial. No lado direito, vemos a natureza em seus detalhes: árvores, rochas, casa.

Assim como o personagem chinês está imerso na natureza, Borges se imiscui entre os escritores, ou melhor, entre os textos, lendas e mitos, reconhecendo viver através deles, emergindo sempre do mundo da cultura.

O mito é maior que a história pessoal, o mito de Buenos Aires é criado para se impor à verdadeira cidade. É como se Borges fosse um pequeno personagem da pintura chinesa, tendo como cenário os contos, as histórias e os sonhos de toda a humanidade, podendo usufruir de várias culturas, servindo-se de todas elas como em um banquete sempre renovado, revivido.

Banhar-se nessas culturas foi, para Borges, uma forma de negar o eu e, ao mesmo tempo, de construir sua possível identidade, respeitada em todo o mundo por ter sido capaz de mobilizar, com extrema clareza, tantos saberes em torno de si. 
CHEREM, L. P. Borges, o eterno caçador...

\section{RESUMO}

Nesse trabalho procuramos estabelecer algumas relações entre a obra de Jorge Luis Borges e o budismo, religião que foi tema estimulante para o autor. As duas principais idéias aqui desenvolvidas são a dissolução do eu e a ilusão da individualidade criadora. Ambas recorrentes em sua obra, tanto em seus textos literários quanto em seus ensaios.

Palavras-chave: literatura latino-americana, universo borgiano, budismo.

\section{RÉSUMÉ}

Dans ce travail, on a voulu établir quelques rapports entre l'oeuvre de Jorge Luis Borges et le bouddhisme, religion qui fut un thème stimulant pour l'auteur. Les deux principales idées dévéloppées ici sont la dissolution du moi et l'illusion de l'individualité créatrice. Toutes les deux sont très présentes dans son oeuvre, aussi bien dans ses textes littéraires que dans ses essais.

Mots-clés: littérature latino-américaine, univers borgien, bouddhisme.

\section{REFERÊNCIAS}

BORGES, J. L. Prólogos com um prólogo dos prólogos. Trad. por Ivan Junqueira. Rio de Janeiro: Rocco, 1985. . Obras completas. Buenos Aires: Emece Editores. t. 1, 1974; t. 2, 1979. . Sete noites. Trad. por João Silvério Trevisan. São Paulo: Max Limonad, 1983. . Obras completas de Jorge Luis Borges. Atlas v. 3. São Paulo: Ed. Globo. ; JURADO, Alius. Buda. Rio de Janeiro: Bertrand Brasil, 1987.

CAHILL, James. Chinese painting. Geneva: Editions dart Albert Skira, 1995.

ERACLE, Jean. Paroles de Buddha tirées de la tradition primitive. Paris: Editions du Seuil, 1991.

FERNANDEZ, Macedonio. Obras completas: relatos cuentos, poemas y miscelánias. t. 7. Buenos Aires: Ediciones Corregidor, 1987. .p. 152.

KERMODE, Frank. Um apetite pela poesia: ensaios de interpretação literária. Trad. por Sebastião Uchoa Leite. São Paulo: Ed. da Universidade de São Paulo, 1993. 
CHEREM, L. P. Borges, o eterno caçador...

PIGLIA, Ricardo. Sobre Borges. Cuadernos de Recienvenido - Borges 100. São Paulo: Humanitas, 1999.

SCHWARTZ, Jorge. Verbete Tigre (Enciclopédia Borges). Suplemento Mais, Folha de S. Paulo, $1 .^{\circ}$ ago. 1999. 